\title{
AGROTEKNOLOGI KOPI GRAFTING UNTUK PENINGKATAN PRODUKSI
}

\section{AGRO-TECHNOLOGY OF COFFEE GRAFTING TO INCREASE YIELD}

\author{
Rusdi Evizal ${ }^{1 *}$ dan Fembriarti Erry Prasmatiwi ${ }^{2}$ \\ 'Jurusan Agroteknologi, Fakultas Pertanian Universitas Lampung \\ ${ }^{2}$ Jurusan Agribisnis, Fakultas Pertanian Universitas Lampung \\ *E-mail: rusdi.evizal@fp.unila.ac.id
}

\begin{abstract}
Lampung Province is the center of Robusta coffee production with an area of 2018 reaching 157.6 thousand hectares while Arabica coffee which has been programmed in 1998 by planting area reached 1.9 thousand hectares did not develop successfully even disappearing. Liberica coffee is commonly grown as a rootstock. This research aims to study the ethno-agronomy of various grafting coffees in Lampung, both Robusta-Liberica and Arabica-Robusta. This research was carried out using Focus Group Discussion (FGD) method with the farmer groups and the observation of coffee plantations in the field belonging to group members in each farmer group selected purposively in each district namely Sekincau Subdistrict of West Lampung, Sumberejo Sub-district of Tanggamus, and Way Ratai Sub-district of Pesawaran, in May-October 2019. The results showed that farmers developed a various of intraspecific coffee grafting (Robusta/Robusta) using a variety of superior local clones and interspecific grafting (Robusta/Liberica and Arabica/Robusta) with specific agronomy practices such as cloning, planting, pruning, fertilizing, applying pesticide, soil conserving, and being non-resident farmers as creations, local wisdom and adaptation of farmers to site-specific conditions.
\end{abstract}

Keywords : Clone, ethno-agronomy, fertilizing, interspesific grafting, local wisdom, rainfall

\begin{abstract}
ABSTRAK
Propinsi Lampung merupakan sentra produksi kopi Robusta dengan areal pada tahun 2018 mencapai luas 157,6 ribu hektar sedangkan kopi Arabika yang telah diprogramkan penanaman sehingga pada tahun 1998 mencapai luas areal 1,9 ribu hektar tidak berhasil berkembang bahkan semakin menghilang. Kopi Liberika umum ditanam sebagai batang bawah. Penelitian ini bertujuan untuk mempelajari agroteknologi kopi grafting yang diterapkan di Lampung baik Robusta, Arabika, dan Liberika. Penelitian ini dilaksanakan dengan metode Focus Group Discussion di kelompok tani dan observasi pertanaman kopi di lapangan milik anggota kelompok pada masing-masing satu kelompok tani yang dipilih secara purposif pada setiap kecamatan yaitu Kecamatan Sekincau, Lampung Barat, Kecamatan Sumberejo, Tanggamus, dan Kecamatan Way Ratai, Pesawaran pada Mei-Oktober 2019. Hasil penelitian menunjukkan bahwa petani mengembangkan ragam grafting kopi intraspesifik (Robusta/Robusta) menggunakan beragam klon lokal unggul serta grafting interspesifik (Robusta/Liberika dan
\end{abstract}


Arabika/Robusta) disertai dengan budidaya spesifik seperti pemilihan klon, penanaman, pemangkasan, pemupukan, aplikasi pestisida, konservasi tanah, berkebun nonresiden sebagai kreasi budidaya, kearifan lokal dan adaptasi petani pada kondisi spesifik lokasi.

Kata kunci: Adaptasi, etnoagronomi, hujan, interspesifik grafting, kearifan lokal, klon, pemupukan

\section{PENDAHULUAN}

Lampung merupakan produsen utama kopi Robusta yang memiliki areal pada tahun 2018 mencapai luas 157,6 ribu hektar terutama di Lampung Barat 54 ribu ha, Tangggamus 41,5 ribu ha, dan Lampung Utara 25,7 ribu ha (Badan Pusat Statistik Provinsi Lampung, 2019). Kopi Arabika yang telah diprogramkan penanaman sehingga pada tahun 1998 mencapai luas areal 1,9 ribu hektar (Badan Pusat Statistik Provinsi Lampung, 2000) tidak berhasil berkembang bahkan tidak tercatat dalam statistik meskipun dalam realitasnya kopi Arabika masih ada dan berproduksi. Hal ini menunjukkan introduksi komoditas baru memerlukan proses adopsi dalam budidaya sesuai dengan kearifan lokal.

Agronomi kopi Arabika sudah tersedia sesuai dengan pedoman GAP berdasarkan Permentan No 49/ Permentan/OT.140/4/2014. Akan tetapi bagaimana orang membudidayakan (etnoagronomi) kopi Arabika di suatu lokasi dapat berbeda sesuai dengan budaya dan lingkungan setempat. Dengan adanya pasar kopi Arabika yang semakin bagus, petani Lampung saat ini kembali mengembangkan pertanaman kopi Arabika antara lain dengan cara mengintegrasikan dengan budidaya kopi Robusta yang telah menjadi kearifan lokal petani kopi Lampung (Evizal, 2013). Selain kopi Robusta dan Arabika, petani Lampung juga bertanam kopi Liberika terutama untuk digunakan sebagai batang bawah (Evizal et al., 2015) yang dikenal sebagai kopi Robinson (Lampung Barat) atau kopi Bariyah (Tanggamus).

Produktivitas kopi tinggi ketika di awal tanaman muda 1-2 kali berproduksi yaitu ketika umur 4-5 tahun karena percabangan buah(cabang B0) tumbuh banyak, berbuku banyak dan siap berbuah. Setelah berbuah lebat tersebut (fase ngagung), cabang ortotrop meninggi pertumbuhan cabang melambat, karena mendukung pembuahan lebat sebelumnya. Apabila keadaan tanah kurang subur, pemberian pupuk kurang cukup, keadaan cuaca ekstrim kering atau basah, atau produksingagung sangat lebat maka sebagian tanaman kopi mengalami mati pucuk yang disebut sebagai gejala over bearing (Evizal, 2018). Selanjutnya produktivitas kopi relatif rendah yang disertai dengan upaya pemangkasan bentuk dan penyambungan (grafting) sampai diameter batang terus tumbuh membesar dan pohon menjadi kokoh. Produktivitas tanaman kopi dewasa atau tua dapat kembali ditingkatkan dengan cara pemangkasan rejuvenasi dan penyambungan sehingga tanaman kembali seperti tanaman muda dalam 2-3 tahun setelah penyambungan dan produksi kembali seperti fase ngagung (Evizal et al., 2010).

Pertumbuhan kopi Robusta dapat dibedakan menjadi (1) fase TBM (umur 1-3 tahun), (2) fase 
ngagung (umur 4-5 tahun), (3) fase tanaman muda (umur 6-15 tahun), (4) fase tanaman dewasa (16-25 tahun), (5) fase tanaman tua (umur $>25$ tahun). Sejak tanaman muda sampai tanaman tua, pemangkasan dan penyambungan terus dilakukan diiringi dengan observasi dan seleksi pohon tetua untuk digunakan sebagai sumber entres baik di kebun sendiri maupun di kebun tetangga dan kerabat sehingga ditemukan banyak klon terutama di Tanggamus dan Lampung Barat (Evizal, 2013; Ramadiana et al., 2018). Penelitian ini bertujuan untuk mempelajari agroteknologi kopi grafting yang diterapkan di Lampung.

\section{BAHAN DAN METODE}

Penelitian ini dilakukan pada bulan MeiOktober 2019 menggunakan pendekatan survei etnoagronomi, dengan mengumpulkan data primer yang diperoleh dari wawancara dan FGD dengan petani dan observasi pertanaman di lapangan di kecamatan sampel dan sekitarnya. Data sekunder diperoleh dari lembaga terkait. Data yang dikumpulkan berfokus pada bagaimana petani bercocok tanam kopi, mulai dari pembibitan, pemeliharaan, pascapanen, pengolahan sampai pemasaran, apa ragam tanaman (jenis dan klon), bagaimana menata tanaman, sistem rotasi tanaman dan rotasi tataguna lahan, apa bahan tanam, apa alat-alat dan saprodi, apa fungsi dan manfaat, apa ragam produk, bagaimana dan kapan pelaksanaan pekerjaan. Survei dilakukan di tiga kecamatan yaitu Kecamatan Sekincau Kabupaten Lampung Barat, Kecamatan Sumberejo Kabupaten Tanggamus, dan Kecamatan Way Ratai Kabupaten Pesawaran dengan mengambil satu kelompok tani pada masing-masing kecamatan yang ditentukan secara purposif. Analisis data dan penyajian dilakukan secara deskriptif.

\section{HASIL DAN PEMBAHASAN}

\section{Tanam Baru dan Peremajaan}

Pembibitan dilakukan di pekarangan rumah atau di kebun yang akan ditanami kopi, dimulai dengan mencari sumber benih dari pohon induk unggul, umur tua, berbuah lebat, dari kopi kultivar Bakir, kedondong dan Garudak (Robusta), atau Robinson (Liberika). Upaya memperoleh bahan tanam mungkin sampai pada lokasi yang jauh yaitu lintas kabupaten atau propinsi. Dipilih buah masak untuk membuat benih berupa biji berkulit tanduk kemudian dijemur beberapa hari. Penyemaian benih dilakukan di bedengan tidak di polibag.

Penanaman baru (new planting) dari pembukaan hutan tidak dapat dilakukan lagi karena terbatasnya lahan. Penanaman dilakukan berupa tanam ulang (replanting) pada lahan semak-belukar bekas kebun kopi tua atau bongkaran kopi tua yang sudah dilakukan beberapa kali penanaman sayur sebagaimana telah dilaporkan Evizal (2013). Membongkar kebun kopi tua dengan tanah yang semakin kurus kemudian diolah dan ditanami sayur secara intensif, selanjutnya disisipi bbit kopi merupakan pengetahuan lokal petani untuk "meremajakan" lahan kebun kopi tua. Sebagai bahan tanam adalah bibit cabutan dari bedengan pembibitan yang sudah disemai 1-2 tahun sebelumnya (advance planting material), dipotong sebagaian akar dan daunnya. Bibit cabutan praktis untuk diikat dan 
dibawa ke kebun yang jauh letaknya. Apabila akar lebih panjang dari lubang tanam maka akar perlu dipotong agar tidak tumbuh membelit. Sebagai pupuk dasar digunakan bahan organik atau pupuk SP36. Penanaman yang dilakukan di akhir kemarau menjelang musim hujan lebih baik daripada dilakukan menunggu musim hujan.

Kebun kopi yang tidak terawat, pohon tinggi, kurang produktif dapat dilakukan rehabilitasi dengan pemangkasan rejuvenasi total dengan memotong pada ketinggian 1 m untuk dipelihara 2-3 tunas air. Kebun yang direjuvenasi dimanfaatkan untuk bertanam sayur. Tunas rejuvenasi akan berbuah dalam 2-3 tahun.Grafting atau penyambungan dilakukan pada kebun rehabilitasi maupun kebun yang akan dilakukan klonisasi. Pada kebun rejuvenasi, tunas-tunas air dilakukan penyambungan. Pada kebun muda atau dewasa yang berasal dari bibit biji, dilakukan pemangkasan dan penyambungan secara bertahap baik secara diupahkan atau dikerjakan sendiri. Petani mengaku 50-100\% pohon kopi di kebun mereka sudah disambung.

\section{Penyambungan}

Penyambungan dilakukan berupa sambung pucuk terdiri dari dua tipe yaitu(1) menggunakan entres ortotrop yaitu dari tunas air dan (2) menggunakan entres plagiotrop yaitu dari cabang yang belum berbuah (cabang B0). Sambung ortotrop membentuk pohon yang meninggi, cocok untuk kebun muda yang masih rapat, pada lahan yang kurang subur, atau pemeliharaan ekstensif. Cabang tidak boleh saling menaungi karena buku akan panjang, batang lemah, dompol renggang dan berisi sedikit buah. Sambung plagiotrop menghasilkan percabangan kipas, yang lebar, jarak perlu agak jauh, sehingga cocok untuk pohon dewasatua dengan lahan yang subur dan pemeliharaan intensif.

Sistem pangkas kapak kulai yaitu untuk rejuvenasi pohon dipotong separuh dan dimiringkan ke

Tabel 1. Karakteristik grafting kopi di Lampung

\begin{tabular}{|c|c|c|c|}
\hline Karakteristik & Sekincau & Sumberejo & Way Ratai \\
\hline Intraspisifik & Robusta/Robusta & Robusta/Robusta & Robusta/Robusta \\
\hline \multirow[t]{2}{*}{ Interspesifik } & Robusta/Liberika & Robusta/Liberika & Arabika/Robusta \\
\hline & Arabika/Robusta & & \\
\hline Sistem grafting dan & Lacuran (ortotrop) dan & Lacuran (ortotrop) dan & Lacuran (ortotrop) dan kipas \\
\hline pangkas & kipas (plagiotrop) & kipas (plagiotrop) & (plagiotrop) \\
\hline Klon Robusta unggul yang & Korolla 1, Korolla 2, & Korolla 1, Korolla 2, & - \\
\hline banyak ditemukan & Korolla 3, Korolla 4 & Korolla 3, Korolla 4 & \\
\hline Klon Robusta lokal & Bodong, Bagio, Darmani, & Blirik, Komari, air dingin, & Kedondong, \\
\hline potensial & Gendot & Tugino & Mekar Sari \\
\hline Kultivar Liberika & Robinson & Bariyah & - \\
\hline Kultivar Arabika & Kartika & - & Kartika, Sigararutang, \\
\hline $\begin{array}{l}\text { Persentase sudah } \\
\text { disambung }\end{array}$ & $80-100 \%$ & $60-70 \%$ & $\begin{array}{l}\text { Andungsari 2K, Komasti, Gayo } \\
50-60 \%\end{array}$ \\
\hline
\end{tabular}


tanah, kadang dilakukan petani apabila pohon yang ingin direjuvenasi sedang berbuah. Dengan pohon terkulai maka tunas-tunas air akan tumbuh, sementara buah dipohon akan tetap masak normal untuk dapat dipanen sementara tunas-tunas air tumbuh siap dipilih untuk menggantikan batang utama.

Batang bawah yang digunakan adalah kopi Robusta dan Liberika dengan karakteristik penyambungan disajikan pada Tabel 1. Sedangkan batang atas yaitu yang menentukan produksi kopi grafting adalah kopi Robusta dan kopi Arabika yang berupa entres klon lokal unggul. Petani memilih pohon induk sebagai bahan klonal adalah pohon yang berbuah lebat, dompol buah besar dan rapat, fluktuasi berbuah yang kecil, percabangan yang kuat, berbuku rapat, tidak banyak tunas wiwilan, ukuran buah sedang sampai besar, tidak berkulit tebal sehingga mudah pecah ketika musim hujan.

\section{Klonisasi}

Agroteknologi penyambungan kopi terkait dengan pemangkasan, rejuvenasi, pemilihan batang bawah, dan klonisasi. Untuk itu perlu tersedia klonklon unggul baik klon nasional maupun lokal. Klon unggul lokal apabila memenuhi syarat dapat dilepas sebagai klon unggul nasional. Beragam klon lokal Robusta digunakan petani sebagai batang atas dengan potensi hasil yang tinggi. Ada 4 klon lokal yang telah dilepas oleh Kementrian Pertanian sebagai klon unggul nasional dengan deskripsi singkat disajikan pada Tabel 2. Klon-klon kopi tersebut dapat dikenali dengan ciri kunci misalnya klon Korolla 1 (Tugu Kuning) buah mudanya berwarna kuning, sehingga kita mengira buah kopi sudah tua karena terlihat kuning tetapi ternyata belum tua. Klon Korolla 2 (Tugu Hijau) dapat dikenali dengan warna buah muda yang hijau, ukuran buah dan biji agak besar. Korolla 3 dapat dikenali dengan bentuk tajuk seperti payung, buah yang bulat, dompolan buah cabang $\mathrm{B} 0$ terbentuk berbarengan antara cabang primer dan sekunder. Klon Korolla 4 dicirikan dengan habitus yang tinggi dan percabangan tegak, cocok untuk tipe grafting ortotrop, bentuk buah mirip dengan kopi lokal kultivar Bakir.

Selain klon-klon unggul yang sudah dilepas sebagai klon unggul nasional, masih banyak klon-klon unggul lokal yang dibudidayakan. Di masing-masing kecamatan terdapat 2-3 klon unggulan yang disukai yang dikenal dengan nama lokal tertentu. Perlu diteliti klon lokal dengan nama yang berbeda apakah memiliki karakteristik fenotip dan genetik beda.

Klon Bodong mudah dikenal dari buah bertipe diskus yang besar dan jelas dengan warna buah muda agak kuning. Klon ini dibudidayakan di Kecamatan Pulau Panggung Tanggamus dan Way Tenong Lampung Barat. Klon Mekar Sari juga bertipe diskus yang besar, buah muda agak hijau, buah masak berkulit tebal dan mudah merekah sehingga disebut Mekar Sari.Klon Darmani dan klon Air Dingin bertipe buah muda berwarna hijau muda dan bergaris putih, tetapi klon Air Dingin memiliki garis-garis kulit buah yang lebih jelas.

Klon Bagio dan klon Tugu Irsad bertipe buah muda berwarna hijau muda dengangaris putih dan diskus yang kurang jelas. Klon Bagio dikenal di Kecamatan Sekincau dan sekitarnya sebagai klon yang 
beradaptasi di wilayah dengan kondisi curah hujan tinggi seperti di Sekincau. Klon Tugu Irsad dikenal dari Desa Sidokayo, Kecamatan Bukit Kemuning Lampung Utara dan menyebar ke Kecamatan Pagar Dewa beradaptasi dengan kondisi kemarau yang tegas untuk dapat berbuah lebat. Klon Gendot bertipe buah muda berwarna hijau agak kuning dan kulit buah bergaris. Di antara klon-klon lokal ini ada yang mampu beradaptasi terhadap cuaca ekstrim namun membutuhkan pemupukan yang cukup sebagaimana dilaporkan Evizal

Tabel 2. Deskripsi singkat klon kopi unggul berasal dari Lampung

\begin{tabular}{|c|c|}
\hline Pelepasan klon & Deskripsi $^{1}$ \\
\hline $\begin{array}{l}\text { Korolla } 1 \text { (nama lokal } \\
\text { Tugu Kuning) dilepas } \\
\text { berdasar Kepmentan No } \\
\text { 35/KPTS/KB.020 2/2019 }\end{array}$ & $\begin{array}{l}\text { Warna flush hijau kecoklatan, buah } \\
\text { berukuran sedang, bentuk bulat, } \\
\text { warna buah muda kuning, diskus } \\
\text { berukuran kecil, biji normal } 75 \% \text {, biji } \\
\text { tunggal } 10 \% \text {, biji gajah } 15 \% \text {, biji } \\
\text { triase } 0 \% \text {, kafein } 1,66 \% \text {, potensi } \\
\text { produksi } 2,09 \mathrm{~kg} \text { biji/pohon/ tahun } \\
\text { setara } 2,87 \text { ton biji/ha/tahun jika } \\
\text { populasi } 1.400 \text { pohon } / \text { ha. }\end{array}$ \\
\hline
\end{tabular}

Korolla 2 (nama lokal Tugu Hijau) dilepas berdasar Kepmentan No 36/KPTS/KB.020/2/2019
Warna flush hijau dan daun tua hijau tua, buah berukuran sedang, bentuk bulat, warna buah muda hijau, diskus berukuran kecil, biji normal 57\%, biji tunggal $22 \%$, biji gajah $21 \%$, biji triase $0 \%$, kafein $1,86 \%$, potensi produksi $2,37 \mathrm{~kg}$ biji/pohon/ tahun setara 3,34 ton biji/ha/tahun jika populasi 1.400 pohon/ha.

Korolla 3 (nama lokal Lengkong) dilepas berdasar Kepmentan No 37/KPTS/KB.020/2/2019

Warna flush hijau muda dan daun tua hijau, buah berukuran sedang, bentuk bulat, warna buah muda hijau, diskus berukuran kecil, biji normal $90 \%$, biji tunggal $2 \%$, biji gajah $8 \%$, kafein $1,21 \%$, potensi produksi $1,69 \mathrm{~kg}$ biji/pohon/ tahun setara 2,36 ton biji/ha/tahun jika populasi 1.400 pohon/ha.

Korolla 4 (nama lokal Bodong Jaya) dilepas berdasar Kepmentan No 38/KPTS/KB.020/2/2019

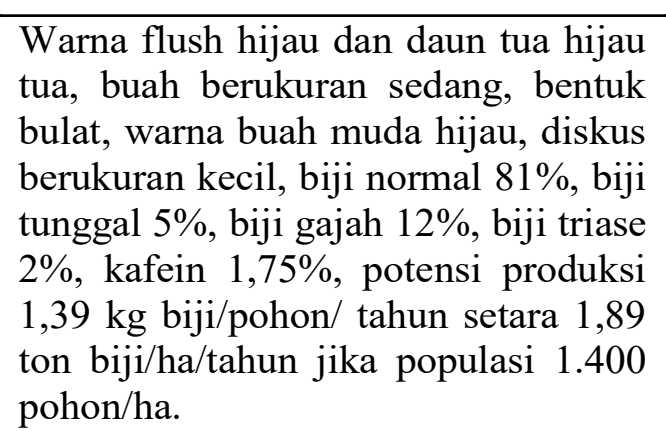

Warna flush hijau dan daun tua hijau tua, buah berukuran sedang, bentuk bulat, warna buah muda hijau, diskus berukuran kecil, biji normal $81 \%$, biji tunggal $5 \%$, biji gajah $12 \%$, biji triase $2 \%$, kafein $1,75 \%$, potensi produksi $1,39 \mathrm{~kg}$ biji/pohon/ tahun setara 1,89 pohon/ha.
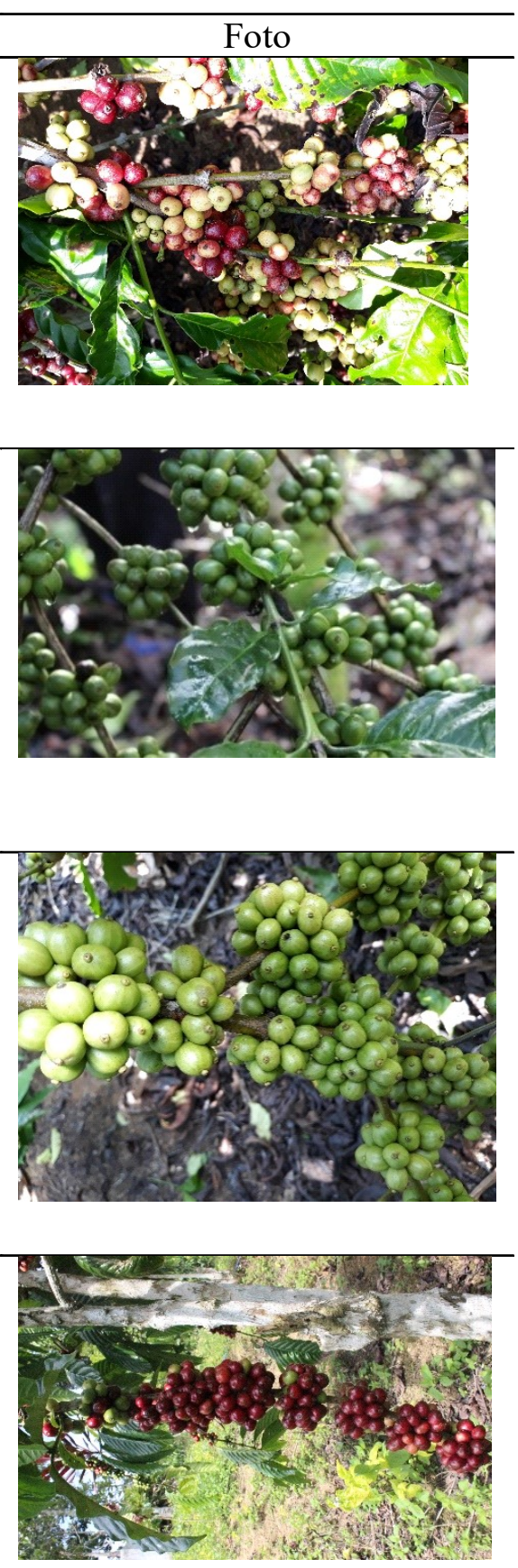
Tabel 3. Deskripsi singkat beberapa klon unggul lokal Lampung




etal. (2020). Martin et al. (2018) menyimpulkan bahwa penanaman klon unggul Robusta merupakan salah satu upaya penting dalam mitigasi variabilitas cuaca.

\section{Grafting Interspesifik}

Pertanaman kopi grafting interspesifik Robusta/ Liberika monokultur dapat ditemukan di Lampung Barat seperti di Kecamatan Sekincau dan sekitarnya. Pertanaman ini sukses berbuah lebat dan berumur panjang sesuai dengan karakteristik keunggulan kopi Liberika sebagai batang bawah. Produksi sangat baik pada tipe pemangkasan dan grafting menggunakan cabang plagiotrop sehingga terbentuk percabangan kipas, kendatipun demikian dapat dilakukan rejuvenasi dan dilakukan grafting dengan cabang ortotrop (Gambar 1). Kopi grafting Robusta/Liberika mudah ditemukan tidak saja di Lampung Barat tetapi juga di Way Kanan dan Lampung Utara karena kopi Liberika ditanam untuk penyulaman kebun tua kemudian disambung dengan kopi Robusta. Penyambungan kopi Arabika/Liberika diakui petani hanya dalam tahap mencoba. Cara penyambungan perlu terus diperbaiki untuk meningkatkan keberhasilan penyambungan sebagaimana Bertrand dan Etienne (2000) melaporkan adanya inkompatibilitas jika dilakukan granfting interspesifikArabika/Liberika.

Penyambungan kopi Arabika menggunakan batang bawah Robusta telah dilakukan petani di Pesawaran dan Lampung Barat dan menghasilkan biji kopi grafting interspesifik Arabika/Robusta dan memberikan hasil yang memuaskan (Gambar 2). Tipe grafting dapat menggunakan entres ortotrop maupun plagiotrop. Kopi Arabika berbatang bawah Robusta menunjukkan keterjadian serangan penyakit karat daun yang lebih rendah daripada kopi Arabika asal biji dan pertumbuhan cabang yang kuat dan daun yang lebih lebar. Lopez-Garcia and Cruz-Castillo (2019) melaporkan kopi grafting Arabika/Robusta berproduksi lebih tinggi daripada kopi Arabika dari biji.

Hasil FGD menunjukkan pembeli dan pengolah kopi Arabika Lampung mengkhawatirkan perubahan citarasa seduhan kopi Arabika grafting interspesifik ini, kendatipun hasil penelitian menunjukkan tidak ada perubahan citarasa kopi Arabika yang dihasilkan seperti dilaporkan oleh Nur et al. (1999) yang bahkan
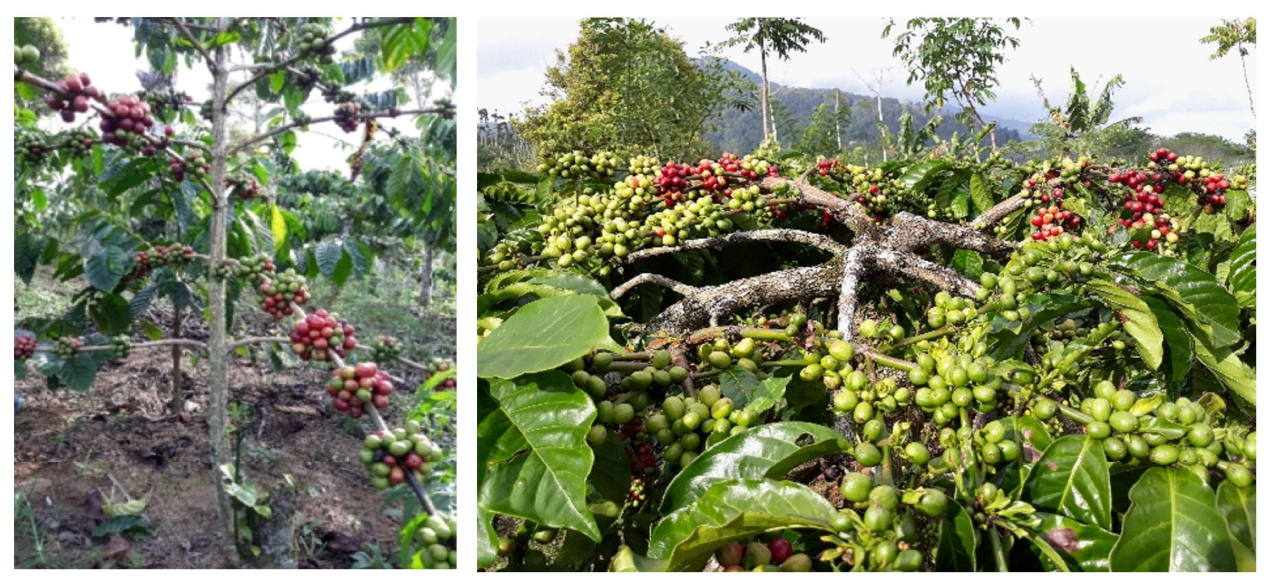

Gambar 1. Grafting Robusta/Liberika dengan entres ortotrop (kiri) dan entres plagiotrop (kanan) 

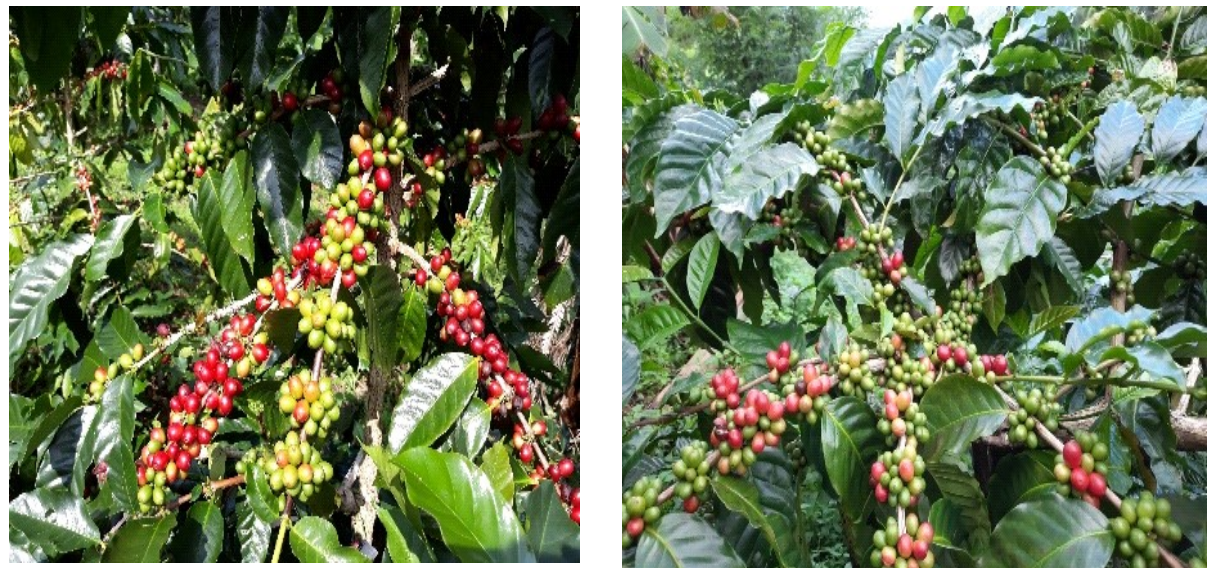

Gambar 2. Grafting Arabika/Robusta dengan entres ortotrop (kiri) dan entres plagiotrop (kanan)

menyatakan bahwa metode ini dapat digunakan untuk mengkonversi pertanaman kopi Robusta menjadi penghasil kopi Arabika. Alnopri dan Hermawan (2015) melaporkan bahwa grafting Arabika/Robusta sebaiknya dilakukan pada pembibitan menggunakan cabang kopi Arabika ortotrop.

\section{Lingkaran Flutuasi Produksi}

Penyiapan percabangan produktif yaitu jumlah dan panjang cabang $\mathrm{B} 0$ serta pemanjangan cabang yang sudah berbuah (B1) bergantung dari cara pemeliharaan terutama pemupukan dan pemangkasan yang benar. Pemupukan yang 5 tepat yaitu jenis, dosis, waktu, cara, dan tempat dapat diterapkan apabila pupuk sudah tersedia sehingga petani kopi yang sukses setiap selesai musim sudah menyiapkan dana pembelian pupuk musim kerikutnya. Dengan pemupukan yang tepat maka akan mendorong pertumbuhan cabang, pembungaan, dan pembuahan sehingga diperoleh produksi yang tinggi setiap tahun 1,5-2 ton per hektar per tahun dan fluktuasi produksi diperkecil. Hasil panen cukup untuk keperluan hidup setahun dan membeli pupuk untuk musim berikutnya.
Hasil FGD mengungkapkan bahwa petani selesai panensebaiknya memiliki simpanan kopi dalam bentuk kopi glondong kering. Untuk memperoleh uang tunai, sebagian kopi dijemur dan digiling menjadi kopi beras untuk diijual. Untuk anggota keluarga dengan 3 orang anak, petani harus menyisihkan 3-4 kuital kopi biji untuk kebutuhan membeli beras, dengan nilai tukar kopi:beras $=1: 2$. Untuk dapat membeli pupuk NPK dan Urea dengan dosis yang cukup maka petani harus menyisihkan 1.5-2 kuintal kopi biji.

Sebaliknya petani yang kurang hasil kopinya, tidak dapat membeli pupuk yang cukup, aplikasi tidak tepat waktu dan jenis sehingga kurang mendorong produksi kopi. Hal inimenyebabkan produksi yang rendah dan fluktuasi antarmusim tinggi. Setelah 1-2 tahun berproduksi rendah, percabangan buah banyak, dan didukung cuaca yang baik maka produksi dapat tinggi mencapai 1-1,5 ton/ha per tahun, namun tahun berikutnya produksi jatuh seperempat sampai separuhnya yaitu 4-7 kuintal/ha. Karena hasil panen sedikit maka petani tidak dapat membeli pupuk, bahkan harus terbelit hutang untuk kebutuhan hidup. 


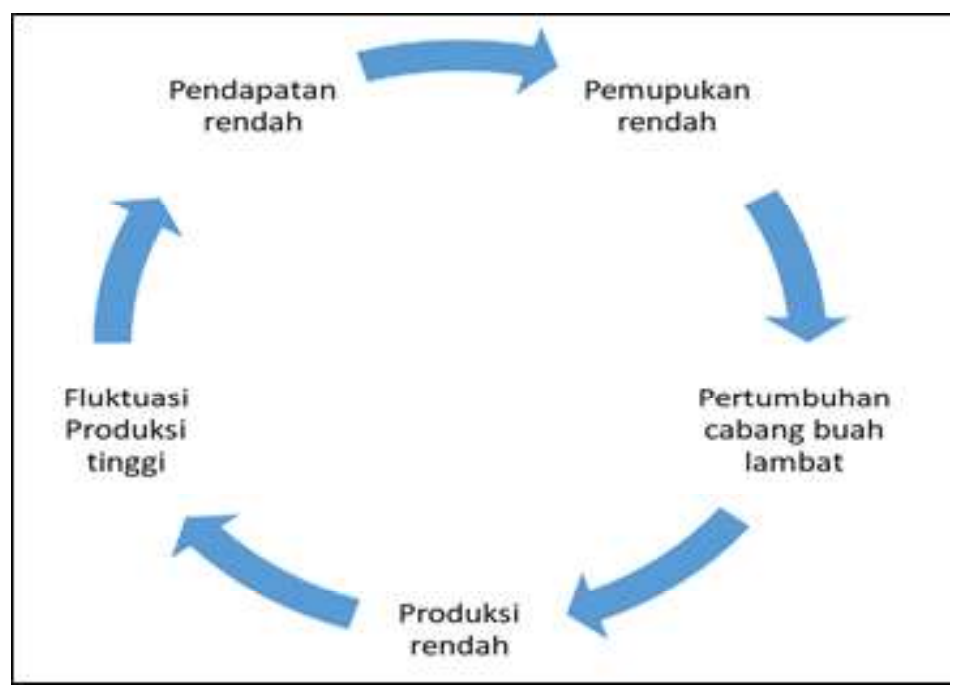

Gambar 3. Pemupukan dan siklus produksi kopi

Hutang tersebut akan dibayar dari hasil panen musim berikutnya. Disini dimulai lagi lingkaran setan kemiskinan petani kopi. Petani ini juga tidak memberi pupuk kandang ke tanaman kopi karena tidak memiliki ternak kambing karena sudah terjual untuk keperluan mendesak seperti keluarga yang sakit atau biaya anak sekolah. Peranan pemupukan tanaman kopi dalam menentukan produksi disajikan pada Gambar 3. Dosis pemupukan yang rendah menyebabkan lingkaran rendahnya produktivitas kopi yang dapat menyebabkan petani terjebak pada lingkaran kemiskinan. Sebaliknya dosis pemupukan dan pemeliharaan yang intensif dapat menghasilkan produktivitas kopi yang tinggi dan fluktuasi hasil yang rendah.

Petani kopi yang lemah secara ekonomi atau tidak mampu mudah terbelit ijon harus berjuang memenuhi kebutuhan hidup umumnya menjadi buruh tani dan jasa ojek angkutan sehingga kebun kopi kurang terawat. Waktu lebih banyak digunakan bekerja di luar kebun kopinya sendiri. Tanaman kopi tidak dipupuk, kurang pemangkasan, dan kurang pengendalian gulma.
Hasil FGD menunjukkan bahwa 25\% petani mengaku tidak melakukan pemupukan, dan $20 \%$ petani hanya melakukan penyiangan secara manual, $45 \%$ petani melakukan penyiangan manual 3-4 kali setahun.

Petani lemah umumnya tidak mampu untuk melakukan tindakan konservasi seperti membuat teras dan rorak. Petani lemah ini memiliki kesempatan terentaskan ketika mendapatkan produksi yang tinggi karena keadaan musim yang baik diiringi dengan harga kopi yang tinggi. Ketika itulah petani mampu memperbaiki rumah, membeli ternak, membeli pupuk dan merehabilitasi kebunnya. Ini merupakan daya tarik mengapa tetap berminat berkebun kopi bahkan pada lokasi yang jauh dari desa tempat tinggalnya, membangun gubuk kerja di kebun, berlaku sebagai petani yang tidak menetap (nonresiden), yang hanya berada di kebun ketika melakukan pekerjaan musiman untuk pemeliharaan dan panen kopi yang disebut tradisi ngumbul yaitu tinggal di kebun untuk sementara waktu. 


\section{KESIMPULAN}

Dari penelitian dapat disimpulkan bahwa petani menerapkan agroteknologi untuk meningkatkan produksiantara lain: (1) melakukanpenyambungan (grafting) kopi intraspesifik (Robusta/Robusta) menggunakan beragam klon lokal unggul nasional dan ungggul lokal; (2) melakukangrafting interspesifik(Robusta/Liberika dan Arabika/Robusta); (3) melakukan pemilihan klon, pemangkasan, pemupukan, aplikasi pestisida, konservasi tanah dan rotasi tataguna lahan sebagai kearifan lokal dan adaptasi petani pada kondisi spesifik lokasi.

\section{DAFTAR PUSTAKA}

Alnopri dan B. Hermawan. 2015. Sustainability for Growth and Productivity of Arabica Coffee in Lowland Regions of Bengkulu Province. International Journal on Advanced Science Engineering Information Technology, 5(5): 304307

Badan Pusat Statistik Provinsi Lampung. 2000. Lampung Dalam Angka 2000. Bandar Lampung. 617 p.

Badan Pusat Statistik Provinsi Lampung. 2019. Lampung Dalam Angka 2019. Bandar Lampung. 417 p.

Bertrand, B. \& H. Etienne. 2000. Growth, production, and bean quality of Coffea arabica as affected by interspesific grafting: Consequences for rootstock breeding. HortScience, 36(2): 269-273.

Evizal, R., Tohari, I.D. Prijambada, J. Widada, F.E. Prasmatiwi dan Afandi. 2010. Pengaruh tipe agroekosistem terhadap produktivitas dan keberlanjutan usahatani kopi. Jurnal Agrotropika, 15(1):17-22.

Evizal, R. 2013. Etno-agronomi Pengelolaan Perkebunan Kopi di Sumberjaya Kabupaten Lampung Barat. Agrotrop, 3(2): 1-12.

Evizal, R., Sugiatno, dan F.E. Prasmatiwi. 2015. Ragam kultivar kopi di Lampung. Agrotrop, 5(1): 8088.

Evizal, R. 2018. Evaluation of FTC Coffee Farm in Semendo, South Sumatra. Faculty of Agriculture, University of Lampung. 21p.

Evizal, R., Sugiatno, S.D. Utomo, H. Pujisiswanto, S. Widagdo, F.E. Prasmatiwi, A.D. Stiawan. 2018. Growth Performance of Mature Trees Resulted from Intra and Inter-specific Grafting on Robusta Coffee. Jurnal Planta Tropika, 6(2): 77-83.

Evizal, R., F.E. Prasmatiwi, S. Widagdo, dan H. Novpriansyah. 2020. Etno-agronomi budidaya kopi yang toleran variabilitas curah hujan. Jurnal Agro Industri Perkebunan 8(1): 51-61.

Lopez-Garcia, F.J. and J.G. Cruz-Castillo. 2019. Yield of Coffea arabica grafted onto Coffea canephora in soils infested with nematodes in Mexico. Coffea Science Lavras. 14(3): 308314.

Martin, L.D., F.C. Eugenio, W.N. Rodrigues, S.V.B. Brinati, T.V. Colodetti, B.F. Christo, D.B.L. Olivas, F.L. Partelli, J.F.T. do Amaral, M.A. Tomaz, J.D.C. Ramalho, A.R. dos Santos. 2018.Adaptation to Long-Term Rainfall Variability for Robusta Coffee Cultivation in Brazilian Southeast. American Journal of Climate Change. 7: 487-504. 
Nur, A.M., Gatut-Supriadji, dan Sulistyowati. 1999. Penelitian konversi kopi robusta ke arabika dengan teknik penyambungan di lapangan. Pelita Perkebunan, 15(1): 1-12.
Ramadiana, R., D. Hapsoro, dan Y. Yusnita. 2018. Morphological variation among fifteen superior robusta coffee clones in Lampung Province, Indonesia. Biodiversitas, 19(4): 14751481. 